\title{
Trends in Female Representation on NCCN Guideline Panels
}

\author{
Pranammya Dey ${ }^{1}$; Angela K. Green, MD, MSc ${ }^{2,3}$; Michael Haddadin, MD;
}

Peter B. Bach, MD, MAPP2; and Aaron P. Mitchell, MD, MPH ${ }^{2,3}$

\begin{abstract}
Background: NCCN produces highly influential disease-specific oncology clinical practice guidelines. Because the number of women in academic oncology has increased, we assessed whether the composition of NCCN Guidelines Panels reflected this trend. Methods: Using historical guidelines requested from NCCN, we investigated time trends for female representation on 21 NCCN Guidelines Panels and analyzed the trends for female-predominant cancers (breast, ovarian, uterine, and cervical) compared with all cancers. Results: From 2013 to 2019, there was an increase from 123 women of 541 total panelists (22.7\%) to 175 women of 542 panelists (32.3\%). Within the 4 femalepredominant cancers, the increase was more rapid: from 30 of 101 total panelists (29.7\%) to 66 of 118 panelists (56.4\%). Excluding femalepredominant cancers, increases were minimal. Conclusions: There could be multiple explanations for these differing trends, including the possibility of more rapid increases in the underlying pool of female physician-scientists in female-predominant specialties or more efforts to increase the representation of women in decisions about the standard of care in cancers predominantly affecting women.
\end{abstract}

J Natl Compr Canc Netw 2020;18(8):1084-1086 doi: $10.6004 /$ jnccn.2020.7571

\footnotetext{
${ }^{1}$ Yale University School of Medicine, New Haven, Connecticut; and

${ }^{2}$ Department of Epidemiology and Biostatistics, and ${ }^{3}$ Department of Medicine, Memorial Sloan Kettering Cancer Center, New York, New York.
}

\section{Background}

NCCN produces the most commonly used clinical practice guidelines in oncology, shaping both clinicians' treatment decisions and payers' coverage decisions. ${ }^{1}$ Each disease-specific guideline is produced by a panel of experts appointed from NCCN Member Institutions.

Previous work has suggested that female representation on NCCN Guidelines Panels tends to reflect the underlying proportion of accomplished female researchers working in each tumor type. ${ }^{2}$ Throughout academic medicine, the proportion of research in prominent medical journals authored by women increased substantially from 1970 to 2014, with the largest increases occurring in specialties with relatively more female physicians, such as obstetrics, gynecology, and pediatrics. ${ }^{3}$ However, barriers to career advancement persist for women, as evidenced by the observation that they are less likely than men to reach full professorship in nearly all subspecialties even after controlling for age, experience, and research productivity. ${ }^{4}$ In addition, women may not be provided the same access as men to highimpact academic work, such as invited commentaries. ${ }^{5,6}$

Our study investigated whether the proportion of women on NCCN Clinical Practice Guidelines in Oncology (NCCN Guidelines) panels is increasing as expected given the increasing percentage of women entering academic oncology and publishing influential research. ${ }^{7}$ In addition, because female representation in 2018 on NCCN Guidelines Panels for gynecologic cancers was considerably greater than for other tumor types, ${ }^{2}$ we also investigated whether any recent increases were concentrated within cancer types that affect predominantly women or were distributed across tumor types. We also investigated whether any increases were distributed across NCCN Member Institutions or concentrated within a few institutions.

\section{Methods}

NCCN Guidelines were requested from NCCN for research use. We included the 21 most prevalent cancers in the United States. Using the first NCCN Guideline for each cancer type published each year from 2013 to 2019, we discerned the sex of panelists based on first name and, 
when uncertain, photos and pronoun descriptors available on institutional web pages. Panelists' institutional affiliations were assigned based on initial appearances in the NCCN Guidelines. Multiple affiliated hospitals for a single medical school were assigned to the medical school. The unit of analysis was the guideline panel position, and therefore the few individuals serving on multiple NCCN Guidelines Panels were counted more than once. We defined "female-predominant cancers" as including breast, ovarian, uterine, and cervical cancers.

\section{Results}

In 2013, there were 123 women among 541 total panelists (22.7\%); in 2019, there were 175 women out of 542 (32.3\%), an annual increase of 1.6 percentage points. Within the 4 female-predominant cancers (Figure 1), the increase was from 30 of 101 (29.7\%) to 66 of 118 panelists (56.4\%), an average annual increase of 4.5 percentage points. However, among the non-femalepredominant cancers, the increase was from 93 of 440 $(21.1 \%)$ to 109 of 425 panelists $(25.6 \%)$, an annual increase of 0.8 percentage points.

The 21 NCCN Guidelines included panelists drawn from the 27 NCCN Member Institutions. The increase of 36 women in female-predominant cancers was distributed across many NCCN Member Institutions; 11 institutions (52\%) added 1 to 2 female panelists to committees for female-predominant cancers during this period, 11 added no women, and only 1 institution (Harvard Medical School) added $>4$.

We found that overall female representation on NCCN Guidelines Panels increased from 2013 to 2019. This rate (1.6 percentage points per year) was similar to that of $1.0 \%$ per year previously observed among oncology trainees and full-time female hematologyoncology faculty. ${ }^{8}$ However, this increase seemed to be driven by the relatively greater increase within the female-predominant cancers compared with other disease sites. Excluding the female-predominant cancers, the increase within other NCCN Guidelines Panels was minimal (see Figure 1).

\section{Discussion}

Several factors may contribute to these trends. For instance, NCCN may have engaged in a conscious effort to increase female representation, and these efforts may have been focused on NCCN Guidelines Panels for cancer types that most commonly affect women. If such efforts have contributed to the observed trends, then our results suggest that they have been largely successful, achieving near parity in the female-predominant cancers by the end of our study period. However, women may still be underrepresented on NCCN Guidelines Panels for

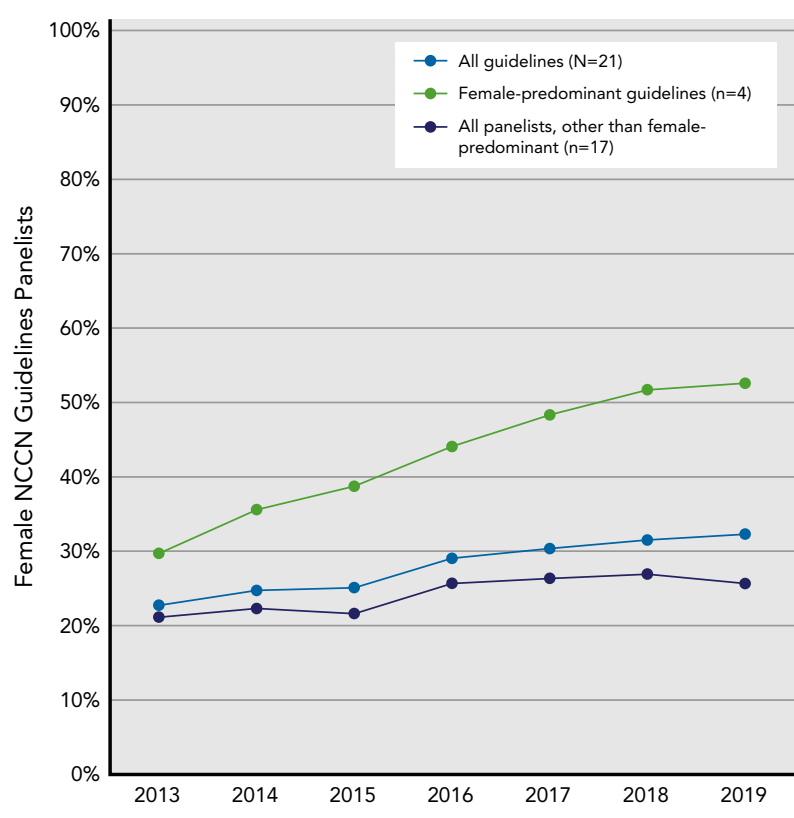

Figure 1. Percentages of female panelists on NCCN Guidelines Panels from 2013 to 2019.

some other cancer types, relative to their scientific activity in those fields. ${ }^{2}$

The observed increase within the female-predominant cancers may also be the result of relatively more female oncologists specializing in these cancers compared with other tumor sites in recent years. Female physician-scientists produce a higher proportion of clinical science in female-predominant cancers, ${ }^{2}$ and the number of female physician-scientists in oncology has sharply increased in the past decade, ${ }^{7}$ coincident with the increase in representation on NCCN Guidelines Panels observed in the current study. In other words, the observed increase may reflect a shifting balance in where female oncologists have chosen to focus their careers. It is possible that the proportion of women working in the female-predominant cancers recently achieved a critical "threshold," in which there are now a sufficient number of mid- and late-career female oncologists to provide strong mentorship and support, making work in these cancer types increasingly attractive to increasingly more early-career female oncologists.

However, to conclude that the representation of women in leadership positions, such as on NCCN Guidelines Panels, may be proportional to their representation in the relevant clinical disciplines does not address the reasons underlying the variation. There may be both positive and negative reasons why a greater portion of female oncologists have recently focused on female-predominant cancer types. As mentioned, women may find stronger mentorship in these 
fields. Female physicians may also feel more invested in caring for female patients, which may have the positive benefit of furthering the therapeutic relationship. However, it may also be the case that careers in other cancer types seem less appealing. Early-career female oncologists may perceive less support and more career barriers in cancer specialties that have historically been, and continue to be, occupied primarily by men.

\section{Conclusions}

Although the overall increase in female representation among NCCN Guidelines Panelists is encouraging, particularly within female-predominant cancers, additional evaluation of biases that may hinder women from entering and achieving appropriate leadership positions in other oncology specialties is warranted.
Submitted December 11, 2019; accepted for publication April 1, 2020

Author contributions: Study conception and design: All authors. Data extraction: Dey, Haddadin. Data analysis: Dey. Interpretation and presentation of results: Dey, Green, Bach, Mitchell. Approval of final manuscript: All authors.

Disclosures: Dr. Bach has disclosed that he receives grant/research support from the Laura and John Arnold Foundation; honoraria from the American Society for Health-System Pharmacists, Gilead Pharmaceuticals, WebMD, Goldman Sachs, Morgan Stanley, Defined Health, Vizient, Anthem, Excellus Health Plan, Hematology Oncology Pharmacy Association, Novartis Pharmaceuticals, Janssen Pharmaceuticals, Third Rock Ventures, JMP Securities, Genentech, Mercer, United Rheumatology, Oppenheimer \& Co. Inc. Cello Health, Magellan Health, EQRx, America's Health Insurance Plans, and Oncology Analytics; and consulting fees from Foundation Medicine and Grail. Dr. Mitchell has disclosed that he receives grant/research support from the Conquer Cancer Foundation, which was funded in part by Merck. The remaining authors have disclosed that they have not received any financial consideration from any person or organization to support the preparation, analysis, results, or discussion of this article.

Correspondence: Aaron P. Mitchell, MD, MPH, Department of Epidemiology and Biostatistics, Memorial Sloan Kettering Cancer Center, 485 Lexington Avenue, Second Floor, New York, NY 10017. Email: mitchea2@mskcc.org

\section{References}

1. Dillmon M, Goldberg JM, Ramalingam SS, et al. Clinical practice guidelines for cancer care: utilization and expectations of the practicing oncologist. J Oncol Pract 2012;8:350-353.

2. Green AK, Barrow B, Bach PB. Female representation among US National Comprehensive Cancer Network guideline panel members. Lancet Oncol 2019;20:327-329.

3. Jagsi R, Guancial EA, Worobey CC, et al. The "gender gap" in authorship of academic medical literature-a 35-year perspective. N Engl J Med 2006; 355:281-287.

4. Jena $A B$, Khullar $D, H o O$, et al. Sex differences in academic rank in US medical schools in 2014. JAMA 2015:314:1149-1158.
5. Thomas EG, Jayabalasingham B, Collins $T$, et al. Gender disparities in invited commentary authorship in 2459 medical journals. JAMA Netw Open 2019;2:e1913682.

6. Loder E, Burch R. Underrepresentation of women among authors of invited commentaries in medical journals-where are the female editorialists? JAMA Netw Open 2019;2:e1913665.

7. Dalal NH, Chino F, Williamson H, et al. Mind the gap: gendered publication trends in academic oncology. Int J Radiat Oncol Biol Phys 2019;105(Suppl):E146.

8. Ahmed AA, Hwang WT, Holliday EB, et al. Female representation in the academic oncology physician workforce: radiation oncology losing ground to hematology oncology. Int J Radiat Oncol Biol Phys 2017;98:31-33. 